English Education Journal

UNNES

http://journal.unnes.ac.id/sju/index.php/eej

\title{
The Role of Representational Meaning of Images in Supporting Ideational Meaning in English in Mind: Students' Book
}

\author{
Fransisca Putri Kartika Cahyani ${ }^{\bowtie}$, Dwi Rukmini, Sri Wuli Fitriati
}

Universitas Negeri Semarang, Indonesia

\begin{abstract}
Article Info
Article History:

Accepted 27

September 2020

Approved 10

December 2020

Published 15 March

2021

Keywords:

Representation, visual metafunctions, representational meaning, linguistic metafunction

Abstract

Textbooks have an essential function to guide students' activities in learning English language and also to provide the materials for teachers in teaching English language. In a textbook, a text is also accompanied by images which can be used to explain the content of the text, or the function of the image is to make the text understandable for the readers. This study investigated visual metafunctions of the images in supporting linguistics metafunction of the texts in students' textbook. The objectives of this study were to explain the representation of representational meanings of the images in supporting the ideational meanings of the texts. Using the framework of Grammar of Visual Design by Kress and Van Leeuwen (2006) and Systemic Functional Linguistics by Halliday (1994) and Eggins (2004), this study used discourse analysis as the research approach. The source was reading texts in English in Mind: Students' Book on Culture in Mind sections. The objects of this study was reading texts which were supported by images. The units were clauses in reading texts and visual items, including vectors, colours, image acts, gazes, size of frames and social distance of the images.The findings revealed that the representational meanings of the images supported the ideational meanings of the texts because the images tried to give depiction of the verbal texts to make the readers could comprehend the texts easily. The presence of narrative representational meaning and the presence of material process inform the situation happened in the stories.
\end{abstract}




\section{INTRODUCTION}

Textbooks have essential functions. They can be used to guide students' activities in learning English language and also to provide the materials for teachers in teaching English. Textbooks serve as the basis for much of the language input learners receive and the language practice that occurs in the classroom (Richards, 2001). Besides, textbooks represent social behaviours, norms, and values in societies through their learning materials (Asriyama, Saleh, \& Fitriati, 2019). Textbooks do not only influence what and how students learn, but also what and how teachers teach (Mahmood, 2011). Textbook is a stimulus or instrument for teaching and learning (Graves, 2000). They can be one of the best source if prepared appropriately in terms of both internal and external structures and visual design, it could be thought as a proficient tool in processes of teaching and learning (Aslan, 2008). A textbook or course book could be a right helper for students in building their interest, motivation, exposure, and curiosity in learning a language (Pertama et al., 2018).

In any learning context, students are usually faced by images which support texts, especially in textbooks they carry around with them. As we know that in a textbook, a text is also accompanied by images which can be used to esxplain the context of the text itself. Then, the function of the image is also to make the text understandable for the readers. Celce Murcia (2001) cited in Widodo (2007) also stated that for teachers, textbooks or course books either required or supplementary provide content and teaching-learning activities, which shape much of what happens in the classroom. Sometimes, we find that images also contain more information than text and that this information can be more easily processed and understood by the observer (Amelsvoort, 2012). Read and Barnsley (1977) cited in Amelsvoort (2012) also found that images only were recalled better than text only, but the combination of images and text were recalled the best of all.
In fact, the combinations of images and texts can develop in meaning-making processes. The presence of multimodality texts can promote, help and contribute in creating and understanding the meanings (Heberle \& Constanty, 2016). The combination can be to or more modes (Kress, 2010). The multimodal studies can be a source of creativity for both teachers and students. The combination of text, audio and image as individual modes and how these can be creatively combined to produce meaning, encourage interaction and learning in the classroom (Marchetti \& Cullen, 2015). In line with Grammar of Visual Design (GVD) draws on Systemic Functional Linguistics (SFL) as theoretical and methodological background for the study of language resources, directly related to the communicative function of language and to the context of communication in which meaning-making processes are constructed (Heberle \& Constanty, 2016). Both theories construct three metafunctions which almost same: ideational, interpersonal and textual in Systemic Functional Linguistcs, while in Grammar of Visual Design has representational, interactive and compositional metafunctions.

Kress and Leeuwen (2006) stated that representational structures in the visual transitivity system or the visual resources for representing interactions and conceptual relations between people, places and things in visual. It also divided into two major processes: conceptual and narrative processes. Then, interactive meaning in grammar of visual design is visual forms of communication which also utilize resources which both constitute and maintain interaction between producer(s) and viewer(s) of a visual. Images represent social interactions and relation through the use of gaze; size of frame; perspective; and vertical and horizontal angles. Therefore, compositional meaning as the ways visuals are composed or structured, and the kinds of meanings conveyed by the various possible compositions.

Furthermore, ideational meaning means that language construes human experience and to convey a picture of reality. Then, 
interpersonal function means that language enacts human relationships to encode interaction and to show how defensible or binding the propositions or proposals. While, in textual function means that language creates discourse which can be used to organize experiential, logical, and interpersonal meaning into a coherent, and in the case of written and spoken language, linear whole.

In general lines, representational /ideational refers to the nature, objects and participants, and circumstance, then interactive/ interpersonal include the relationship between the viewer and the represented participants, and compositional/textual concerned with the information value emphasis among elements of the image (Heberle \& Constanty, 2016).

This study aimed to represent representational meaning of the images in supporting ideational meaning of the texts in students' textbook, especialy in Culture in Mind section of English in Mind: Students' Book. This study used to prevent misinterpretation the message of images which supports texts so that the learners could inrerpret them well. According to Pourrajab and Rabbani (2015) stated that images in the textbooks influence the learning process and they also revealed that pictures in textbooks could increase students' creativity.

\section{METHODS}

This study is discourse analysis approach to analyse, describe and interpret the data. It is a Multimodal Discourse Analysis which focuses on the visual metafunctions in supporting linguistics metafunctions. According to Jones (2012) Multimodal Discourse Analysis is concerned with theory and analysis of semiotic resources and the semantic expansions which occur as semiotic choices combine in multimodal phenomenon. O'Halloran (2011) also stated that Multimodal Discourse Analysis is an emerging paradigm in discourse studies which extends the study of language in combination with other resources, such as images, scientific symbolism, gesture, action, music and sound. In line with the statement, textbooks belong to an example of discourse study which extends the study of language in combination with other resources, such as the combination of images and texts.

The data are taken from reading texts in English in Mind: Students' Book on Culture in Mind sections. There are 7 reading texts. The texts are chosen to be identified in forms of clauses, phrases, and words, and also visual items, including vectors, colors, image acts, gazes, size of frames and social distance of the images.

Once the data are gathered, the researcher conducts several steps. The first is determining the linguistics modes and visual modes in students' textbook. The linguistics modes are provided in reading text, while the visual modes are provided in the images of the participants as the depiction of the content in the texts. The second is identifying and classifying images based on the theory of Grammar of Visual Design by Gunther Kress and van Leeuwen, while, in identifying and classifying texts are based on the theory of Systemic Functional Linguistics. The third is conducting questionnaire to the users of textbooks, they are the eighth grade students of SMP Kebon Dalem Semarang. The questionnaire relates to the users' understanding in using textbook and the questions are designed according to the meanings' relation that are experienced by the learners.

\section{RESULTS AND DISCUSSIONS}

Using the Grammar of Visual Design theories proposed by Kress and Leeuwen (2006), representational meaning related to the internal relations between the represented participants, things, and the actions they perform as well as the setting of the circumstances. The internal relation of visual images can be divided into two patterns, narrarive and conceptual representational process. This study finds that in term of representational meaning, narrative representational process is more dominant than conceptual representational process. The findings are presented in the Table 1. 
Table 1. Summary of representational meaning in images

\begin{tabular}{llll}
\hline \multicolumn{1}{c}{ Source } & \multicolumn{3}{c}{ Representational Meaning } \\
\hline \multirow{2}{*}{ Text 1 } & \multicolumn{2}{c}{ Narrative Representational } \\
\cline { 2 - 2 } An unusual hobby & $\begin{array}{l}\text { Conceptual Representational } \\
\text { Attributive) }\end{array}$ & (Symbolic \\
\hline Text 2 & Narrative Representational & \\
\cline { 2 - 4 } Helping at a hospital & $\begin{array}{l}\text { Conceptual } \\
\text { Attributive) }\end{array}$ & Representational & (Analytical \\
\hline
\end{tabular}

\section{Text 3}

The ping pong friendship that changed the Narrative Representational world

\begin{tabular}{llll}
\hline \multirow{2}{*}{$\begin{array}{l}\text { Text } 4 \\
\text { In New York for New Year's Eve }\end{array}$} & \multicolumn{3}{l}{ Narrative Representational } \\
\cline { 2 - 4 } & $\begin{array}{l}\text { Conceptual } \\
\text { Attributive) }\end{array}$ & Representational & (Symbolic \\
\hline Text 5 & $\begin{array}{l}\text { Conceptual } \\
\text { Reggae music }\end{array}$ & Representation & (Symbolic \\
\hline \multirow{2}{*}{$\begin{array}{l}\text { Attributive) } \\
\text { Subway hero } 6\end{array}$} & Narrative Representation & \\
\cline { 2 - 4 } & $\begin{array}{l}\text { Conceptual } \\
\text { Attributive) }\end{array}$ & Representation & (Analytical \\
\hline Text 7 & Narrative Representation & \\
Heroic Ulises on a journey of hope & Conceptual & Representation & (Analytical \\
& Attributive) & & \\
\hline
\end{tabular}

According to Pahlevi (2018) stated that narrative process presents the development of actions and events. In narrative process serves to present actions and events, that is doing by the represented participants. The actor is the represented participant which emanates the vector, while the goal is the represented participant at which the vector is aimed. Kress \& Van Leeuwen (2006) stated that narrative process is when participants are connected by a vector, they are represented as doing something to or for each other. It presents unfolding actions and events, processes of change and also transitory special arrangement. Kress \& Van Leeuwen (2006) cited in Yang \& Zhang (2014) stated that vectors, as the distinctive feature of narrative process, is usually realized by elements appearing in pictures that form "an oblique line, often a quite strong, diagonal line". Vector makes an important role to explain the representational meanings of the images in supporting ideational meanings of the texts. It can be used to define the representational meanings presented in the images. It can be shown in Figure 1. 


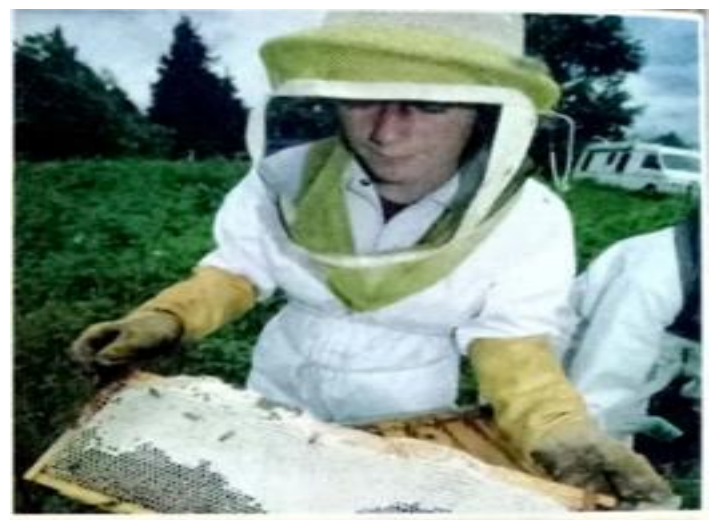

Figure 1. The example of narrative representational process

The picture shows that the represented participant holds a board with her hands. It forms a vector. The represented participant is the actor while her hands and the board act as the vector by forming the oblique line (the goal). The board has many bees to stick on it and produce the honey. It represents the activity of beekeeping. The represented participant also wears a special hat, cloth, and gloves to cover her body from the bees.

Furthermore, there is also an image which applies narrative process in term of action process. It can be seen in Figure 2.

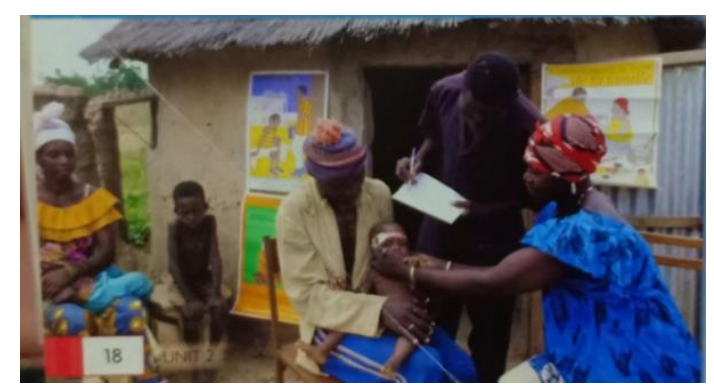

Figure 2. The example of narrative representational process

The picture presents people in the image focuses on the baby. The woman in blue checks the baby by holding the baby's cheeks and her hands forms a vector. While, man in white holds the baby in his thighs. The woman in blue and white is as the actor, while the baby is as the goal. It represents the activity of checking health and in the image focuses on the health of the baby.
Moreover, conceptual process is comprised of classificational process, analytical processes and symbolical processes ( $\mathrm{Hu} \& \mathrm{Luo}$, 2016). Based on the findings, the reading texts apply both of them, analytical and symbolical processes. Analytical processes relate participants in terms of a part-whole structure and involve two kinds of participants, Carrier as the whole and any number of Possessive Attributive as the parts of something (Kress \& Van Leeuwen, 2006). It can be seen in Figure 3.

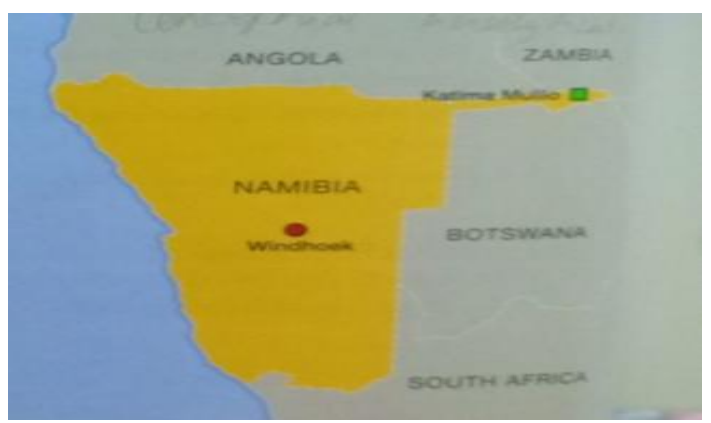

Figure 3. The example of analytical process

This picture shows a map which represent analytical attributive process because it belongs to the parts of something, it is the part of certain region.

While symbolic process is about what a participant means or is (Kress \& Van Leeuwen, 2006), it means that to represents the identity of the represented participants. It can be seen in Figure 4.

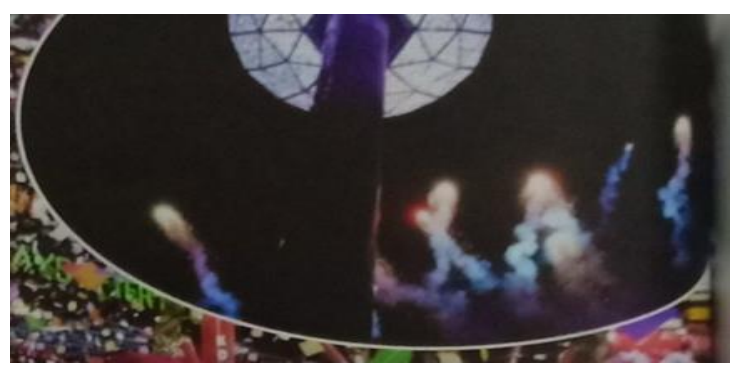

Figure 4. The example of symbolic attributive process

Based on the findings, symbolic process is more dominant than analytical process in the images. The picture in figure 4 shows that the white lamp lights on the top of the pole and the 
sky is dark. It is also the lights of the fireworks in the sky. It represents the identity of the event that happened at night.

In line with representational meaning of the images, this study also conducts the analysis of ideational meanings of the texts. There are several processes of transitivity, such as material, mental, verbal, behavioural, relational (identifying and attributive) and existential processes. The findings are presented in Table 2 .

Table 2. Summary of Ideational meaning in texts

\begin{tabular}{|c|c|c|c|c|c|c|c|c|}
\hline \multirow{2}{*}{ Source } & \multirow{2}{*}{ Material } & \multirow{2}{*}{ Mental } & \multirow{2}{*}{ Verbal } & \multirow{2}{*}{ Behavioural } & \multicolumn{2}{|c|}{ Relational } & \multirow{2}{*}{ Existential } & \multirow{2}{*}{$\begin{array}{l}\text { Total } \\
\text { of } \\
\text { clauses }\end{array}$} \\
\hline & & & & & Identifying & Attributive & & \\
\hline Text 1 & 19 & 7 & 5 & 1 & 5 & 5 & & 42 \\
\hline Text 2 & 24 & 4 & 1 & & 3 & 4 & 1 & 37 \\
\hline Text 3 & 20 & 4 & 6 & & 2 & 3 & 1 & 36 \\
\hline Text 4 & 11 & & 2 & & 3 & 4 & & 20 \\
\hline Text 5 & 7 & 5 & 1 & & 7 & 2 & 1 & 23 \\
\hline Text 6 & 24 & 6 & 3 & 2 & 10 & 8 & & 53 \\
\hline Text 7 & 23 & 3 & 1 & & 6 & 3 & 1 & 37 \\
\hline Total & 128 & 29 & 19 & 3 & 36 & 29 & 4 & 248 \\
\hline $\begin{array}{l}\text { Value in } \\
\text { percentage }\end{array}$ & 51.6 & 11.7 & 7.7 & 1.2 & 14.5 & 11.7 & 1.6 & 100 \\
\hline
\end{tabular}

From the analysis, it is found that the ideational meaning of the text consists of several processes of transitivity. The findings present that material process is the most dominant of the transitivity and followed by identifying as the relational process. Material processes are processes of doing-and-happening (Halliday \& Matthiessen, 2004). It is about doing, about action (Eggins, 2004). It contributes to develop the plot of the situations by telling the readers about actions carried out by the represented participants, such as "She feeds the bees with sugar and water", "In the afternoon, Claire stays in her room", "Zedong gave Cowan a silk scarf", "He jumped", "Subway workers helped the two men out.

While identifying process is that ' $x$ serves to define the identity of $y$ ' (Eggins, 2004). It means that identifying process is a process to give the identity of something. Furthermore, the findings show that text 2 (Helping at a hospital) and text 6 (Subway Hero) has 24 clauses that apply the material process, such as, "He is working in a hospital near Katima Mulilo", "Sometimes I go to villages in the mobile hospital, too", "He jumped", "Subway workers helped the two men out", "An ambulance took Mr. Hollopeter to hospital". The verbs work, go, jump, help, take belong to the activities. They construes a quantum of change in the flow of events as taking place through some input of energy (Halliday \& Matthiessen, 2004). "He", "I", and "An ambulance" are as actors, that is the one that does the deed, that brings about the change (Halliday \& Matthiessen, 2004). While, in the sentences "Claire Williams is 15", "She is from Wales", "It was 12.45 p.m. on 2 January, 2007", "It was a frightening moment" are examples of identifying as relational processes. It means that the Value of the sentences (15, from Wales, 12.45 p.m. on 2 January 2007, a frightening moment) define the identity of the Token (Claire Williams, She, it) that stands for what is being defined. 
The findings show that the presence of narrative representational meaning are in line with the presence of material process as the domination process that are found in the verbal text to tell and inform the situation happened in the story. In Pahlevi (2018) also found that material process is the most dominant used to shows a process of doing something. As stated by Gerot and Wignell (1994), material processes express the notion that some entity physically does something which may be done to some other entity. While the presence of symbolic attributive as the conceptual representational meaning of the images do support the verbal texts which depict the participants that involved in the verbal texts. In line with Ahmadi, Yazdani, Babasalari, \& Rabi (2019) found that material process outnumber other processes in the studied lessons text of Persian textbook, then the second frequently process is relational process (attributive and identifying). Thus, the images of the findings which exist in the texts do support the verbal texts presented because the images try to give depiction of the verbal texts to make the readers can comprehend the texts easily.

\section{CONCLUSION}

Theoretically, this study contributes to enrich the study of multimodality, especially in the representation of visual metafunctions in supporting linguistics metafunctions that are provided in English textbooks.

This study found that the representational meanings of the images support ideational meanings of the texts. It can be seen from the images of the findings which exist in the texts do support the verbal texts presented because the images try to give depiction of the verbal texts to make the readers can comprehend the texts easily. The presence of narrative representational meaning is in line with the presence of material process as the domination process that are found in the verbal text to tell and inform the situation happened in the story.

The result will be useful to know many modes of multimodality in meaning making process through images and texts in a textbook. It is also useful to provide the beneficial information about multimodality. It can be used to consider the appropriate teaching material in English, especially in connecting the variety of modes without eliminating the meaning of the images or texts.

\section{REFERENCES}

Ahmadi, H., Yazdani, S., Babasalari, Z., \& Rabi, A. (2019). Representation Meaning of Multimodal Discourse in Textbooks: A Case Study of Persian Language-Learning Textbook. 16(1), 12-21.

Amelsvoort, M. Van. (2012). Images and Memory: A Literature Review of Issues in the Use of Images to Aid Vocabulary Acquisition and Reading Comprehension and Recall. Pref.Kanagawa.Jp, 19-31.

Aslan, C. (2008). Issues on Education and Research. May 2014.

Asriyama, W. F., Saleh, M., \& Fitriati, S. W. (2019). Multimodal Representation of Gender in Two Senior High School English Textbooks. 10(1), 115-123.

Eggins, S. (2004). An Introduction to Systemic Functional Linguistics 2nd Edition. Continuum

Gerot \& Wignell. (1994). Making Sense of Functional Grammar. Cammeray NSW: Antipodean Educational Enterprises.

Graves, K. (2000). Designing Language Courses. Heinle \& Heinle Publishers.

Halliday, M. A. K., \& Matthiessen, M. I. . (2004). Introduction to Functional. December.

Heberle, V. M., \& Constanty, V. (2016). Meaning without words : analyzing the picture book Bárbaro through a social semiotic perspective. 2011.

Hu, C., \& Luo, M. (2016). A Multimodal Discourse Analysis of Tmall's Double Eleven Advertisement. English Language Teaching, 9(8), 156.

Jones, R. H. (2012a). Multimodal Discourse Analysis. The Encyclopedia of Applied Linguistics. 
Kress, G. (2010). Multimodality_A Social Semiotic Approach to Contemporary Communication. Routledge.

Kress, G., \& Van Leeuwen, T. (2006). Introduction: The Grammar of Visual Design. Reading Images: The Grammar of Visual Design .

Mahmood, K. (2011). Conformity to Quality Characteristics of Textbooks: The Illusion of Textbook Evaluation in Pakistan. 5(2), 170190.

Marchetti, L., \& Cullen, P. (2015). A Multimodal Approach in the Classroom for Creative Learning and Teaching. 39-51.

O'Halloran, K. L. (2008). Systemic functionalmultimodal discourse analysis (SFMDA): Constructing ideational meaning using language and visual imagery. In Visual Communication (Vol. 7, Issue 4).

Pahlevi, S. R. A. (2018). The Ideational Meaning of Text and Image Relation in Bahasa Inggris for Tenth Graders. 8(3), 317-323.

Pertama, T., Rukmini, D., Anggani, D., \& Bharati, L. (2018). Implementation of Three
Metafunctions in Verbal Language and Visual Image of Students' Textbook. 8(4), 418-431.

Pourrajab, M., \& Rabbani, M. (2015). Effects of pictures in textbooks on students'. 4.

Richards, J. C. (2001). role-of-textbooks in a language program_Richard.pdf. 1-6.

Susanto, D. A., \& Watik, S. (2017). The Interpersonal Meaning Realized in The Lyrics of Christina Perri's Album "Lovestrong" and The Contribution for Teaching a Modern English Grammar. Deiksis, 9(03), 283.

Widodo, H. P. (2007). Textbook Analysis on College Academic Writing. TEFLIN Journal, 18 Number, 109-122.

Yang, J., \& Zhang, Y. (2014). Representation Meaning of Multimodal Discourse-A Case Study of English Editorials in The Economist. Theory and Practice in Language Studies, 4(12), 2564-2575. 